\title{
Poor perceptions and expectations of asthma control: Results of the International Control of Asthma Symptoms (ICAS) survey of patients and general practitioners
}

\author{
David Bellamy ${ }^{\mathrm{a}, *}$, Tim Harris ${ }^{\mathrm{b}, 1}$
}

\author{
a James Fisher Medical Centre, 4 Tolpuddle Gardens, Bournemouth BH9 3LQ, UK \\ b GlaxoSmithKline, Greenford, UK
}

Received 14 March 2005; accepted 11 April 2005

KEYWORDS

Asthma;

Asthma corcrol;

Asthma mañjement;

Lifestyle;

Survey;

Symptoms

\begin{abstract}
summararal Practice
Aiirs. To assess current levels of as thria control and to identify barriers to optimal asthma manalyeinent.

Alediad: Q. Survey was conducted of 802 asthma patients (via computer-aided telephone interviewing) and 809 general practitioners (GPs; via the internet) from the UK, Italy, France, Germany, Spain, Canada and Australia.

Results: Over three-quarters (82\%) of patients surveyed reported an absence of asthma control, with the vast majority $(80 \%)$ experiencing subsequent lifestyle restrictions. Although most (58\%) GPs questioned believed that total asthma control was possible, half (52\%) agreed that their patients were not achieving best possible asthma control.

Conclusions: Action is required to encourage patients to view their asthma more seriously and to be more proactive in reporting symptoms to their GP. These actions, coupled with greater prompting of patients by GPs about their asthma, should help to optimize asthma management.

(c) 2005 Published by Elsevier Ltd on behalf of General Practice Airways Group.
\end{abstract}

\section{Introduction}

Asthma affects an estimated 300 million people worldwide, with an additional 100 million cases

\footnotetext{
* Corresponding author. Tel.: +44 1202 522622; fax: +44 1202548580 .

E-mail address: david.bellamy@virgin.net (D. Bellamy).

1 Present address: 14 Dean Close, Uxbridge UB10 9LB (Tel.: +44 (0) 1895 465132; e-mail: timjharris@mac.com).
}

predicted by 2025 [1]. Asthma impacts significantly on patient quality of life and healthcare resources [2], accounting for approximately one in every 250 deaths worldwide and with approximately 15 million disability-adjusted life years lost to asthma per year [1].

Although the majority of patients seen in primary care have mild-to-moderate asthma, many patients are failing to achieve established 
global standards for asthma management [2]. This has been demonstrated in several international surveys including the Asthma Insights and Reality in Europe study, in which nearly half of the 2,800 patients surveyed reported daytime symptoms of asthma and almost a third reported asthmarelated sleep disturbances [3]. Also, patients' perception of asthma control did not match their symptom severity, with approximately half of those patients reporting severe symptoms considering their asthma to be completely or well controlled [3]. Other studies, carried out in America [4], Asia-Pacific [5] and the UK [6], have demonstrated a comparable shortfall in asthma control.

Following the publication of updated Global Initiative for Asthma (GINA) asthma management guidelines in 2002 [2], the International Control of Asthma Symptoms (ICAS) survey was conducted in order to capture a 'snapshot' of the attitudes of both patients and general practitioners (GPs) to asthma control, including evaluation of current levels of asthma control and identification of barriers to optimal asthma management.

\section{Methods}

\section{Selection of subjects:}

Eight hundred and two asthin (1) atients from the UK, Italy, France, Germany, Spain, Canada and Australia participated in the ICAS patient survey, which was conducted between 19th and 30th November 2003 by Taylor Nelson Sofres plc using computer-aided telephone interviewing. All respondents were taken from household survey panels specific to each country. Patients were eligible for inclusion if they were aged over 16 years and self-identified as having occasional or mild-to-moderate asthma. They were not screened according to smoking status. Quotas were not applied for male:female ratio and since the main contact approached in France was the housewife, most of the respondents there were female. Response rates were not measured.

Eight hundred and nine GPs from the UK, Italy, France, Germany, Spain, Canada and Australia participated in the ICAS GP survey, which was conducted on-line by Taylor Nelson Sofres plc. All GPs had to see at least one asthma patient per month to be eligible to participate. In France, Germany and the UK, GPs were sampled using internet GP panels, while in Australia, Canada, Italy and Spain, GPs were pre-recruited by telephone. In Canada, quotas were applied on French versus
English speakers in order to be representative of the GP population. In each country, a regional spread of respondents was achieved. Response rates were not measured. Assessment of response rates was not possible when sampling GP internet panels, since more GPs were asked to participate than were included in the final analysis in order to achieve the required sample size.

\section{Questionnaire design}

The questionnaire was designed to examine both patient and GP perceptions of asthma control in the light of revisions to asthma management guidelines published by GINA in 2002 [2]. Survey questions were not validated.

The agencies conducting the fieldwork were responsible for translating the questions using language that was clear, current and appropriate for the audience. In order to ensure both accuracy of translations and cultural/organizational variations, translations were then checked by an independent source, usually a native speaker resident in the UK, and anv changes Inade by the checker were agreed with the asericy

Definition: (if astanla control (patient survey) and totál asthma control (GP survey) were developec vilín E-Tisideration to GINA guidelines for as (h.ma management and prevention [2]. The defirition of asthma control used in the patient survey originally included classification of patients according to measurement of peak expiratory flow (PEF). However, these results were excluded from the final analysis of asthma control as many patients had difficulty answering this question given their limited knowledge of the importance of regular PEF or spirometry measurements.

In the patient survey, asthma control (maintained over an 8-week assessment period) was defined as: no use of blue inhaler/reliever medication; no symptoms such as breathlessness, wheeziness, coughing or chest tightness; no night-time awakenings due to asthma; and no asthma attacks resulting in the need for oral steroids or hospital admission. People with lifestyle restrictions were defined as those answering 'yes' to any of the following questions. Do your asthma symptoms ever wake you at night or early in the morning? Do they restrict your sporting activities, impinge on your enjoyment of sports or affect you when you are playing sport? Do they embarrass you in social situations or restrict your social life? Do they mean you have to use your blue inhaler/reliever more than 2 days a week? Do they bother, irritate or frustrate you in your everyday life? Do they stop you having 
sex or getting full enjoyment from your sex life? Do they make you think twice about trying new sporting activities, or prevent you from trying altogether? Patients responding 'yes' to using their blue inhaler/reliever more than 2 days a week but 'no' to all other questions were excluded from this category.

In the GP survey, total control of asthma (maintained for at least 7 weeks over an 8week assessment period) was defined as: no daily symptoms; no night-time awakenings due to asthma; no exacerbations; no rescue salbutamol use; no emergency visits; greater than $80 \%$ PEF (measured in the morning); and no treatmentrelated adverse events forcing a change in asthma therapy.

\section{Results}

\section{Patient survey}

Demographics for the patients surveyed are provided in Table 1.

\section{Asthma control}

The majority (82\%) of all patients survayec recorted an absence of asthma aphtiot With individual country figuresiar $\mathrm{g}$. Australia $(F-0.01$ versus Fran $\&$ an 1 it itaty; $P<0.05$ versus the UK) (Fig. 1).

A similar proportion ( $80 \%$ of all patients) reported lifestyle restrictions due to asthma.

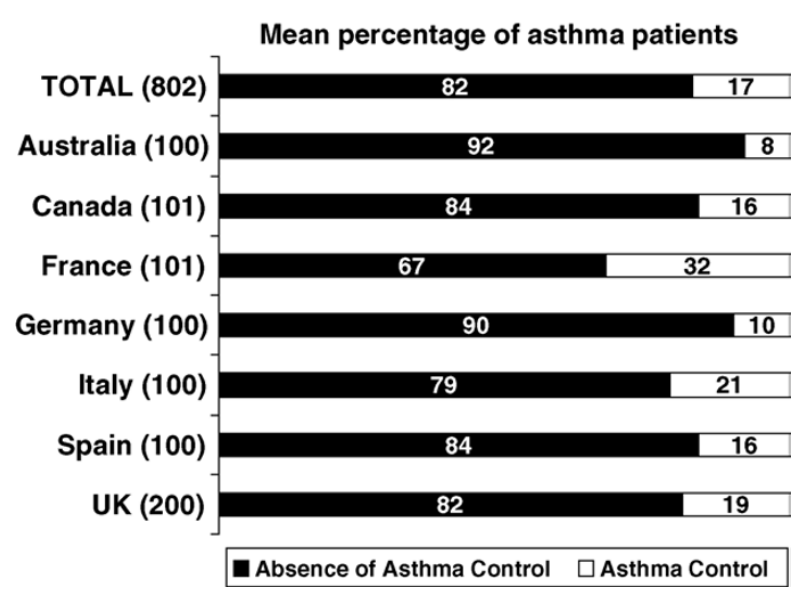

Figure 1 Patient survey. Proportion of patients reporting asthma control/absence of asthma control.

The most commonly reported lifestyle restrictions (Table 2) were night-time or early-morning awakening (48\%), bother, irritation or frustration with everyday life (48\%), and restriction of sporting activities (47\%).

Many respondents had experierced symptoms of asthma over the pre iev's 8. Weeks (Table 3), with 74\% reportiog Breathlessness, wheeziness, colgr.ing or chest tightness, and $62 \%$ using their blue inhalerfielerer more than once.

\section{Experience, expectation and ambition}

The vast majority of patients (94\%) agreed that they would like to live without asthma symptoms and 91\% said that they would consult their GP if they felt that this was possible. However, $90 \%$ said that

Table 1 Demographics of patient sample.

\begin{tabular}{|c|c|c|c|c|c|c|c|c|}
\hline & \multirow[b]{2}{*}{ Total } & \multicolumn{7}{|c|}{ Country } \\
\hline & & Aus & Can & Fra & Ger & Ita & Spa & UK \\
\hline Number of patients & 802 & 100 & 101 & 101 & 100 & 100 & 100 & 200 \\
\hline \multicolumn{9}{|l|}{$\operatorname{Sex}(\%)$} \\
\hline Male & 26 & 36 & 21 & 1 & 29 & 38 & 26 & 30 \\
\hline Female & 74 & 64 & 79 & 99 & 71 & 62 & 74 & 71 \\
\hline \multicolumn{9}{|l|}{ Age (\%) } \\
\hline $16-24$ & 8 & 10 & 7 & 1 & 7 & 11 & 13 & 10 \\
\hline $25-44$ & 41 & 47 & 40 & 47 & 52 & 36 & 46 & 30 \\
\hline $45-64$ & 31 & 36 & 40 & 28 & 23 & 23 & 21 & 41 \\
\hline $65+$ & 19 & 7 & 14 & 25 & 18 & 30 & 20 & 21 \\
\hline \multicolumn{9}{|l|}{ Household size (\%) } \\
\hline 1 person & 15 & 10 & 18 & 17 & 21 & 12 & 6 & 17 \\
\hline 2 persons & 29 & 20 & 40 & 38 & 23 & 23 & 18 & 37 \\
\hline $3+$ persons & 55 & 70 & 43 & 46 & 56 & 65 & 76 & 47 \\
\hline Average number in household $(n)$ & 2.9 & 3.4 & 2.6 & 2.7 & 2.8 & 3.1 & 3.4 & 2.7 \\
\hline
\end{tabular}

Base: All respondents; Aus = Australia; Can = Canada; Fra = France; Ger= Germany; Ita = Italy; Spa = Spain. 
Table 2 Proportion of patients reporting lifestyle restrictions.

\begin{tabular}{|c|c|c|c|c|c|c|c|c|}
\hline & \multirow[b]{2}{*}{ Total } & \multicolumn{7}{|c|}{ Country } \\
\hline & & Aus & Can & Fra & Ger & Ita & Spa & UK \\
\hline Number of patients & 802 & 100 & 101 & 101 & 100 & 100 & 100 & 200 \\
\hline \multicolumn{9}{|c|}{ Percentage of respondents answering 'yes' to each question: Does your asthma: (\%) } \\
\hline Wake you at night or early in the morning? & 48 & 56 & 44 & 38 & 54 & 35 & 66 & 45 \\
\hline $\begin{array}{l}\text { Restrict your sporting activities, impinge on your } \\
\text { enjoyment of sports or affect you when you are } \\
\text { playing sports? }\end{array}$ & 47 & 54 & 48 & 50 & 53 & 42 & 55 & 36 \\
\hline $\begin{array}{l}\text { Embarrass you in social situations or restrict your } \\
\text { social life? }\end{array}$ & 24 & 19 & 27 & 27 & 11 & 24 & 48 & 20 \\
\hline $\begin{array}{l}\text { Mean you have to use your blue inhaler/reliever } \\
\text { more than } 2 \text { days in a week? }\end{array}$ & 46 & 67 & 50 & 26 & 28 & 28 & 73 & 48 \\
\hline Bother, irritate or frustrate you in everyday life? & 48 & 51 & 48 & 49 & 65 & 35 & 58 & 38 \\
\hline $\begin{array}{l}\text { Stop you having sex or getting full enjoyment from } \\
\text { your sex life? }\end{array}$ & 9 & 8 & 6 & 3 & 18 & 12 & 17 & 6 \\
\hline $\begin{array}{l}\text { Make you think twice about trying new sporting } \\
\text { activities, or prevent you from trying altogether? }\end{array}$ & 33 & 27 & 29 & 37 & 39 & 32 & 41 & 32 \\
\hline
\end{tabular}

Base: All respondents; Aus = Australia; Can = Canada; Fra = France; Ger = Germany; Ita = Italy; Spa = Spain.

they expected to have these symptoms as part of having asthma and $87 \%$ felt that although today's treatments would reduce their asthma symptoms, they could not completely eradicate them. In addition, $90 \%$ of patients surveyed agreed that if a medicine was available that could enable thein to live life without asthma svinf tere, hisey would want their GP to prescilibejit.

The activitw the snost respondents) (5;\%) said that they would like to do more, or feel more able to do if they did not have asthma, was sport. Other activities that patients would like to do more included social ictiviti=s $(34 \%$ ), family responsibilities (26\%) and work (26\%). There was corlside oble variation in the responses between cicuntries; for ekrimple, $49 \%$ of German patients wante $\mathrm{d}$ tol be more involved in family activities ( $P<0.01$ versus France, Australia, Canada, Spain and the UK) compared with only $8 \%$ in France.

Table 3 Proportion of patients experiencing symptoms over the previous 8 weeks.

\begin{tabular}{llllllllll}
\hline & \multicolumn{9}{c}{ Country } \\
\cline { 3 - 8 } & Total & Aus & Can & Fra & Ger & Ita & Spa & UK \\
\hline Number of patients & 802 & 100 & 101 & 101 & 100 & 100 & 100 & 200
\end{tabular}

Percentage of respondents answering 'yes' to each question (experienced over the previous 8 weeks):

Have you: (\%)

Used your blue inhaler/reliever more than once?

Experienced any symptoms such as

62

breathlessness, wheeziness, coughing or chest tightness?

Been woken at night as a result of your asthma?

Measured your peak flow and found it to be less than $80 \%$ ?

Had an asthma attack that resulted in you being prescribed a course of oral steroids at one or more occasions?

Had an asthma attack that resulted in your being admitted to hospital on more than one occasion?

$\begin{array}{llllllll}62 & 84 & 62 & 46 & 66 & 46 & 57 & 67 \\ 74 & 87 & 80 & 59 & 85 & 65 & 64 & 74 \\ 27 & 32 & 22 & 14 & 31 & 28 & 36 & 26 \\ 11 & 8 & 4 & 5 & 17 & 15 & 10 & 14 \\ 6 & 7 & 7 & 6 & 13 & 9 & 7 & 1 \\ 1 & 1 & - & - & 1 & 1 & 4 & -\end{array}$

Base: All respondents; Aus = Australia; Can = Canada; Fra = France; Ger= Germany; Ita = Italy; Spa = Spain. 
Thirty-seven per cent of patients said that they did not generally report their symptoms (or their impact) to their GP while $22 \%$ stated that they did not discuss asthma symptoms with their GP because they did not believe anything could be done to prevent them. There was considerable variation in these responses according to country, with $14 \%$ in Germany stating that they did not generally report symptoms to their GP compared with $54 \%$ in Australia $(P<0.01$ versus Germany, Italy, France, Spain and Canada). The proportion of patients who did not discuss their symptoms because they felt they were not preventable ranged from $13 \%$ in Italy to $37 \%$ in Spain $(P<0.01$ versus Italy, Germany and Canada; $P<0.05$ versus Australia and the UK). Of those patients who did not discuss their symptoms with their GP, $43 \%$ (ranging from $7 \%$ in France to $86 \%$ in Germany) said that this was because they could get a repeat prescription for their asthma, $33 \%$ (ranging from $14 \%$ in Germany to $67 \%$ in France) did not regard their asthma as important enough to warrant seeing their GP, and $11 \%$ (ranging from $0 \%$ in Germany to $30 \%$ in Spain) commented that their doctor did not question them about their asthma.

Almost one in five respondents $(19 \%)$ had not discussed their asthma with a healthcare professional since they were diagnosed. Of those respondents who discussed their asthma symptoms with their GP, the frequency of discussion varied between countries, with most patients in Australia discussing their asthma every 4-6 months, compared with patients in Italy discussing their asthma at least once a month.

\section{GP survey}

On average, the GPs participating in the survey were seeing 27 asthma patients per month. Of these, the vast majority (88\%, range $85-90 \%$ ) were classified by their GPs as having mild-to-moderate asthma (Fig. 2a).
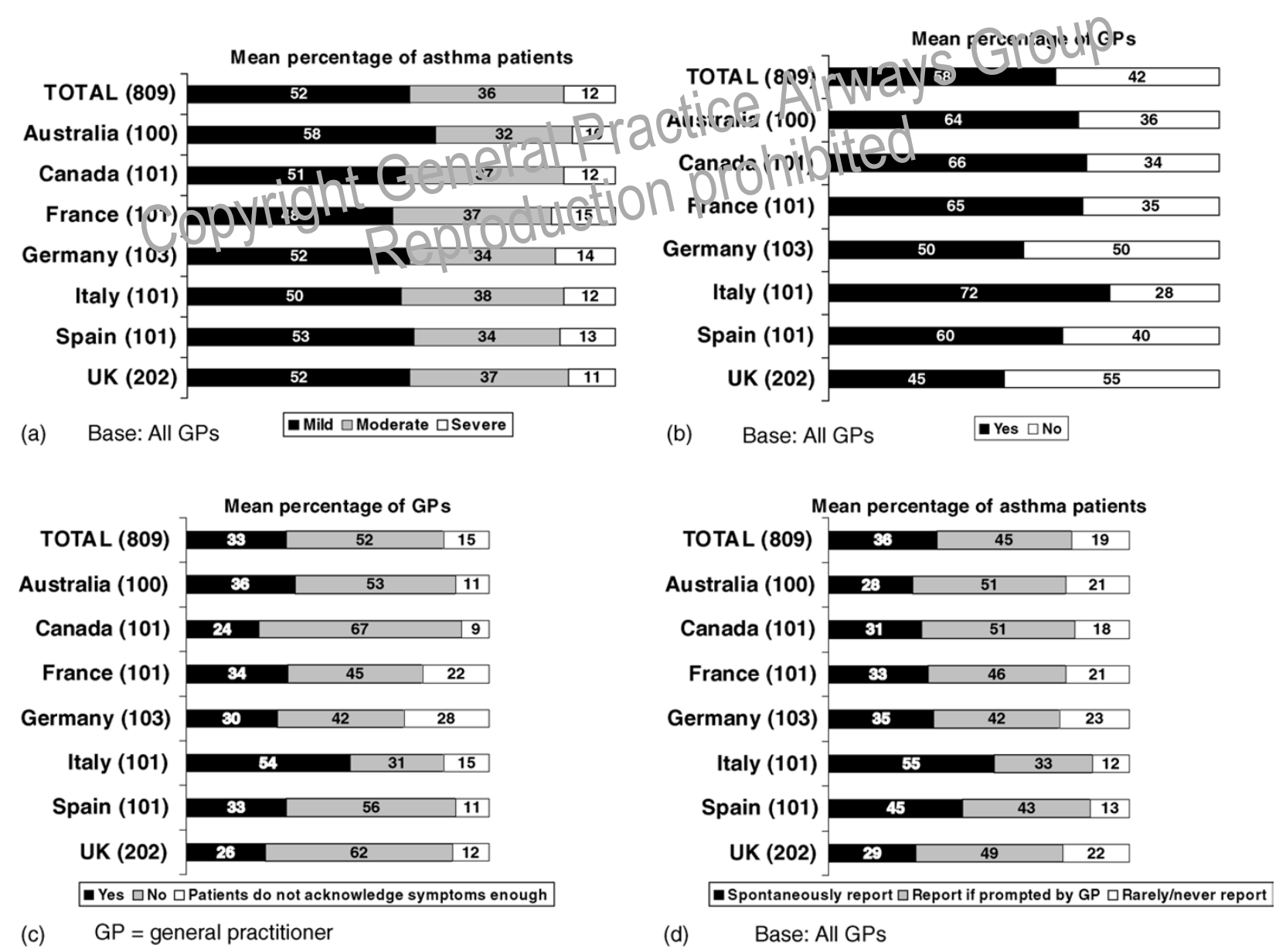

Figure 2 GP survey (a) Severity of asthma patients seen by GPs surveyed. (b) Proportion of GPs who believe that total control of asthma is possible. (c) Proportion of GPs who believe that the majority of their asthma patients are achieving the best control they can achieve. (d) Opinion of GPs on how their patients report symptoms 


\section{Asthma control}

The majority of GPs surveyed (58\%) believed that it was possible to achieve total control of asthma each day for 7 weeks out of 8 (Fig. 2b), with individual country figures ranging from $45 \%$ in the UK to $72 \%$ in Italy $(P<0.01$ versus Germany and the UK).

Of those GPs who thought it was possible to achieve total control, $62 \%$ believed that the majority of their patients were currently achieving total asthma control. This number varied considerably by country, ranging from $39 \%$ in Spain to $78 \%$ in Australia. However, while nearly $90 \%$ of asthma patients seen by the GPs questioned were considered as having mild-to-moderate asthma, $52 \%$ of GPs agreed that their patients were not achieving the best asthma control they could achieve, and a further $15 \%$ said that their patients did not acknowledge their symptoms enough for their GPs to know if they were receiving best possible asthma control (Fig. 2c).

\section{Reporting of symptoms}

More than two-thirds (68\%) of GPs were concerned that patients accepted their symptoms as normal and over half $(55 \%)$ of them reported that they would like their patients to be more forthcoming during a consultation. Nearly a third (31\%) गा GPs were concerned that their patients avee nct being explicit about the bynptons they were experiencing on a dity.to.tay basis and $17 \%$ apred that they were rustrated by the fact that their patients were not forthcoming with all of their symptoms. These figures were higher in Australia and Canada, with half of the GPs surveyed in each country concerned that patients were not being explicit about their symptoms $(P<0.01$ versus France, Germany, Italy and Spain) and nearly a third expressing frustration that their patients were not more forthcoming about their symptoms (Australia: $P<0.01$ versus France, Germany, Italy, Spain and the UK; Canada: $P<0.01$ versus France, Italy and Spain and $P<0.05$ versus the UK). Only $11 \%$ of all GPs (ranging from 3\% in Australia and Spain to 30\% in Italy $[P<0.01$ versus Australia, Canada, France, Spain and the UK and $P<0.05$ versus Germany]) did not have any of the concerns described above.

GPs also noted that patients often underestimated the seriousness of asthma, with only approximately a third of patients spontaneously reporting their symptoms to their GP (Fig. 2d).

\section{Discussion}

These results highlight inadequacies in current levels of asthma control and identify some important barriers limiting optimal management of the condition. Although the majority of patients being seen by GPs have mild-to-moderate asthma, most patients reported an absence of asthma control and many reported significant lifestyle restrictions. Too many patients have symptoms that they accept as being part of the condition and many rely too heavily on their rescue medication. These findings corresponded with high levels of concern amongst GPs that patients accept their symptoms as normal and frustration that their patients were not more forthcoming about their symptoms. Most GPs believed that it was possible to achieve total control of asthma, which is supported by findings from a recent study evaluating guideline-defined asthma control [7]. Hence, the results of this ICAS survey underline the need for a more proactive approach from patients to take their asthma more seriously, coupled with more prompting from GPs in order to establish more accurately their patients' levels of asthma control.

Although the main findings were generally consistent across the countries surveyed, some country-specific trends were obseryed, indicating that factors such as culturalcinilerences and prescribing pautro, should also be taken intel corsideration when drawing up national recommendâtion: focasthma control. Restriction of iportirgactivities was the most commonly reported lifesiyle restriction in patients from France and Italy, whereas frustration experienced in everyday life was more of a concern in Germany, and having to use rescue medications more than two days in a week was more of a concern in Spain, Australia, Canada and the UK. In Spain, over four times the number of patients felt that asthma restricted their social life compared with those in Germany, while in Germany, six times as many patients stated that asthma restricted their sex life compared with those in France. The patient survey also highlighted some important differences in prescribing patterns. For example, $13 \%$ of patients in Germany reported an asthma attack in the last eight weeks resulting in prescription of an oral course of steroids, compared with only $1 \%$ in the UK. Also, the majority $(86 \%)$ of patients surveyed in Germany stated that they could get a repeat prescription for their asthma rather than discussing asthma symptoms with their doctor - this compared with only $7 \%$ in France. Reliance on rescue medication also varied between countries: in Australia, $84 \%$ of patients had used their blue inhaler/reliever more than once in the last 8 weeks compared with $46 \%$ in France or Italy.

In conclusion, more than three-quarters of patients who participated in the ICAS survey reported an absence of asthma control, with the vast majority 
experiencing lifestyle restrictions due to asthma. Although the majority of GPs questioned believed that total control of asthma is possible, most agreed that their patients did not achieve this objective.

Action is required to encourage patients to take their asthma more seriously and to consult more readily with their GP in order to maximize asthma control. Increased awareness of the seriousness of asthma, a more proactive approach from patients in reporting their symptoms, and greater prompting of patients by GPs about their asthma, may help to optimize asthma management.

\section{Conflicts of interest}

DB has received sponsorship for major respiratory meetings and lecturing for a range of pharmaceutical companies.

\section{Acknowledgement}

Source of financial support: This survey was sponsored by GlaxoSmithKline plc.

\section{References}

[1] Masoli M, Fabian D, Holt S, Beasley R. Global burden of asthma. Developed for the Global Initiative for Asthma. 2004. Available at: http://www.ginasthma.com/ (accessed 1-7-2004).

[2] National Institutes of Health. Global Initiative for Asthma. Global strategy for asthma management and prevention. 2002. (Updated from: NHLBI/WHO Workshop Report: Global Strategy for Asthma Management and Prevention Issued January, 1995. NIH Publication No 023659).

[3] Rabe KF, Vermeire PA, Soriano JB, Maier WC. Clinical management of asthma in 1999: the Asthma Insights and Reality in Europe (AIRE) study. Eur Respir J 2000;16: 802-7.

[4] Asthma in America $^{T M}$. 2005. Available at: http://www. asthmainamerica.com/ (accessed 1-7-2004).

[5] Lai CKW, on behalf of the AIRIAP Steering Committee. Clinical management of asthma in Asia-Pacific in 2000: the asthma insights and reality in Asia-Pacific (AIRIAP) study. Eur Respir J 2001;18:441s.

[6] King J, Browning DC, Martin AA, Shrewsbury SB. Is asthma well controlled in primary care clinics? Baseline results from the Patient Outcomes Measurement Study (POMS). Eur Respir J 2000;16(Supplement 31):33s.

[7] Bateman ED, Boushey HA, Bousquet J, et al. Can guidelinedefined asthma control be achieved? The Gaining Optimal Asthma Control study mp (mes, prit Care Med 2004;170:836

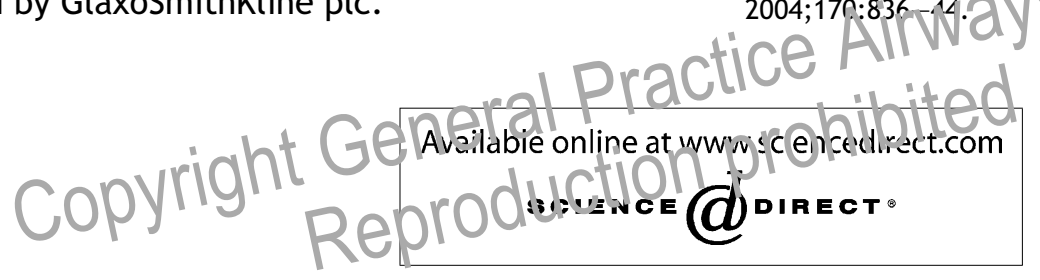

Available online at http://www.thepcrj.com 